\title{
Trial overstated HRT risk for younger women
}

\author{
Cite as: CMAJ 2017 May 1;189:E648-9. doi: 10.1503/cmaj.1095421
}

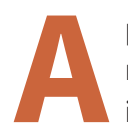
principal investigator of a landmark women's health study says initial results that linked hormone replacement therapy (HRT) to breast cancer and heart attacks were misleading and distorted for publicity. Others involved in the study claim the findings were merely misunderstood. Fifteen years on, a new consensus about risks and benefits is emerging, but too late for a generation of women who abandoned or avoided HRT due to reported risks.

"Highly unusual circumstances" surrounding the early termination and reporting of the Women's Health Initiative (WHI) estrogen-progestin trial in 2002 resulted in "misinformation and hysteria" that persist today, says Robert Langer. He was lead investigator of a WHI vanguard site and involved in early leadership of the study, including as chair of the principal investigators committee.

"Good science became distorted and ultimately caused substantial and ongoing harm to women for whom appropriate and beneficial treatment was either stopped or never started," Langer wrote in a recent review in Climateric.

In June 2002, Langer and other WHI investigators gathered at a semi-annual meeting in Chicago, only to discover that the estrogen-progestin trial was stopping early. Langer says the decision was "based on a finding of likely futility," not harm. But an initial results paper and press release - written in secret by a small group of study executives - cited an increase in breast cancer as the main reason for terminating the trial. It also cited an increase in heart attacks.

However, "the study results were not statistically significant for breast cancer harm," or for heart attacks, says Langer. In fact, the only significant findings were an increase in venous blood clots and a reduction in hip fractures.

There were other problems, too. The

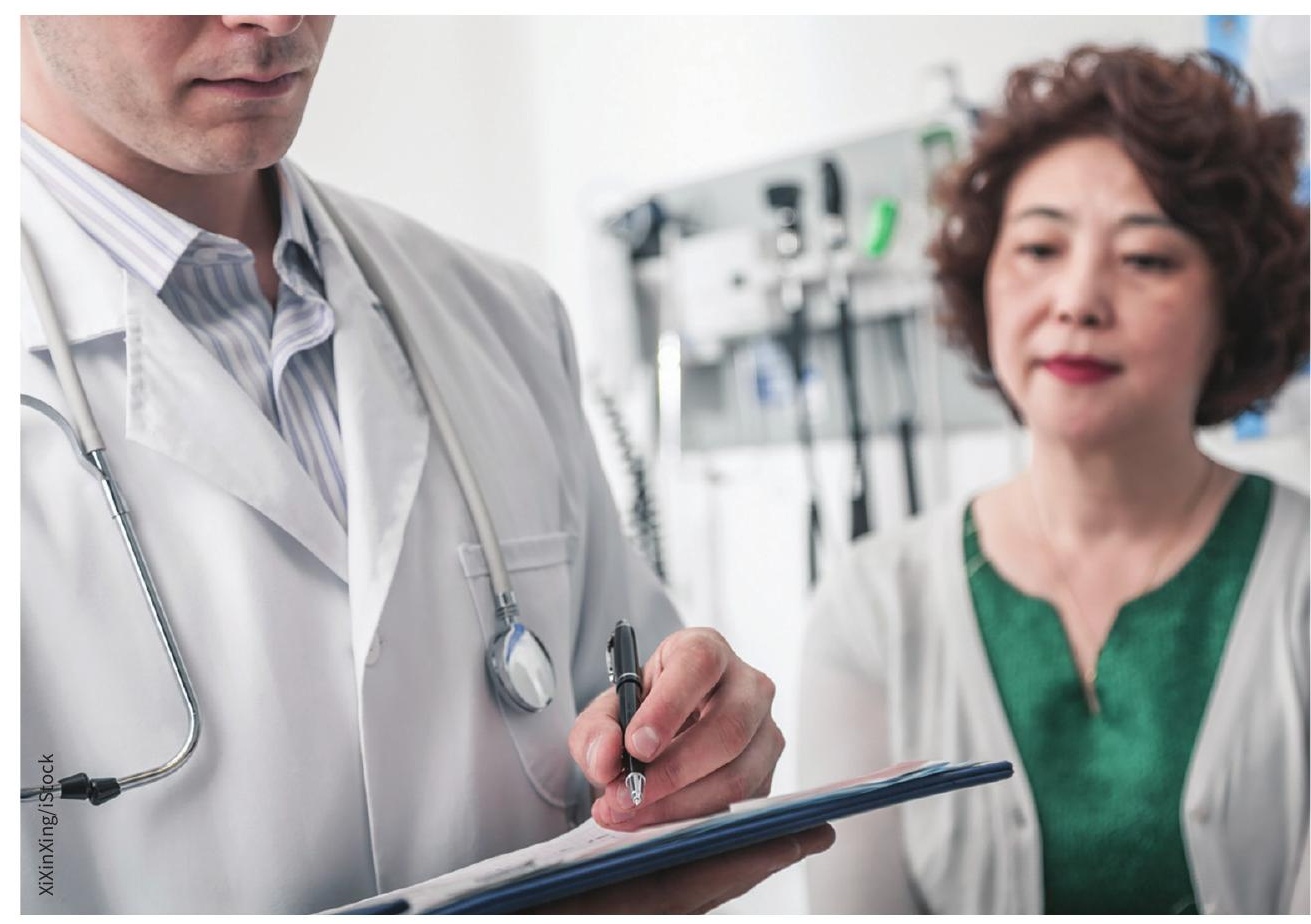

Results of a major trial of hormone replacement therapy may have been misleading.

results weren't adjusted for factors like the participants' pre-existing diseases or treatments besides hormones, and may have been skewed by an unusually low rate of breast cancer in the placebo group, Langer says.

There were also mixed messages about whether the findings applied to all women taking estrogen and progestin. The trial was designed to focus on long-term hormone therapy to prevent chronic disease in women over age 60, but the results were generalized to younger women on shortterm therapy for symptoms of menopause. Only $30 \%$ of the study participants were aged 50 to 59, the years in which most women undergo the treatment.

Later analysis of WHI data showed these younger women had an absolute risk of 12 adverse events per 10000 women less than a third of the risk of adverse events noted among women aged 70 to 79 - as well as fewer cancers, fractures and deaths from any cause compared to the placebo group.

These nuances were muddied in the paper and its press release which Langer says favored "fear and sensationalism over science," overstating the breast cancer risk in a bid to court "maximum publicity." The investigators at the Chicago meeting scrambled to draft changes that were couriered to JAMA, where the paper was set for imminent publication, but it was too late. The journal had gone to print. The media picked up the narrative that HRT causes breast cancer and heart disease. For better or worse, it stuck, and use of the treatment plummeted by as much as $80 \%$.

Dr. Jacques Rossouw, chief of the WHI branch at the United States National Institutes of Health, says the writing group knew the paper and press release would provoke a strong reaction "proportional to the size of the dogma it overturned."

Up to that point, doctors and medical 
societies had supported long-term use of hormone therapy in older women, particularly to prevent heart disease. All debate aside, the WHI showed that estrogen plus progestin didn't prevent heart attacks in women over 60 , and the risks of the treatment increased with long-term use and age.

"We knew that this was an important finding," Rossouw says. "We wanted to make sure it got the widest possible exposure, and we achieved that objective. Now, were we wrong to do that? We feel that we had little alternative because we needed to change a practice that turned out to be incorrect."

The writing group kept the findings secret, even from most of the WHI investigators, in order to protect study participants from learning the results from an unofficial source, Rossouw adds. "I leave it to you to judge how much of this was people feeling that they were left out, versus a genuine issue with the way the data were presented."

Rossouw agrees that many women and doctors now believe that "hormone therapy in general is dangerous," even though the risks in younger women "are indeed extremely low."

"The WHI, including myself, have somehow been blamed," but the backlash "is not in our control," he says. "It's the professional societies to which these doctors belong that need to make sure that practice conforms to the evidence." Rossouw also faults the media for using "headlines that scare people because it gets hype."

He says the writing group was "careful to say that this was a trial of disease prevention in older women." But things aren't so clear cut in the WHI's initial press release. At one point, the release states that the benefits of estrogen plus progestin are "likely to outweigh the risks" for short-term relief of symptoms of menopause. But later it states that "the adverse effects of estrogen plus progestin applied to all women, irrespective of age, ethnicity, or prior disease status." Both statements were attributed to Rossouw.

Dr. JoAnn Manson, another WHI investigator, says there were "a number of factors that spun out of control" to cause misunderstanding of the findings. She was Langer's coauthor on a 2013 review and primary author of a 2016 perspective in the New England Journal of Medicine that attempted to set the record straight on the benefits of short-term hormone therapy for symptoms of menopause.

However, Manson declined to comment on Langer's new allegations. "It is extremely political. Bob Langer, he's no longer really actively involved in WHI, but I am," she explained. "What we're trying to do now is look to the future."
Medical societies have come around again to recommend short-term hormone therapy for women within 10 years of menopause. But care for midlife women is still "quite fragmented and derailed," Manson says. Many doctors are reluctant or lack the training to prescribe appropriate hormone therapy, she says. At the same time, there's been an explosion in the market for unproven alternative treatments.

Dr. Jennifer Blake, CEO of the Society of Obstetricians and Gynaecologists of Canada (SOGC), says experts are only beginning to realize the harms of younger women stopping and avoiding appropriate hormone therapy. "Death rates go up when you stop hormones and we have lots of evidence to show hip fracture risk goes up as well."

A study published in 2013 estimated that as many as 91610 American women died prematurely between 2002 and 2012 as a result of avoiding estrogen therapy.

Dr. Robert Reid, lead author of the SOGC menopause guidelines, says "it probably did more harm than good telling everyone to stop their hormones."

\section{Lauren Vogel, CMAJ}

This is a two-part article on hormone replacement therapy. Part two will look at a resurgence of interest in the preventive use of HRT. 